\title{
A FORMAÇÃO INICIAL DE PROFESSORES DE GEOGRAFIA NA PERSPECTIVA DOS EGRESSOS DO PIBID-UNIOESTE
}

The initial formation of Geography teachers in the perspective of the graduates of PIBID-UNIOESTE

\author{
Eliete Woitowicz * \\ Marli Terezinha Szumilo Schlosser ** \\ *Doutoranda em Geografia, UNIOESTE/Francisco Beltrão - eliete_wgeo@hotmail.com. \\ ** Doutora em Geografia, UNIOESTE/Francisco Beltrão - marlisch20@hotmail.com.
}

Recebido em 31/07/2018. Aceito para publicação em 20/08/2018.

Versão online publicada em 03/09/2018 (http://seer.ufrgs.br/paraonde)

\begin{abstract}
Resumo:
O presente trabalho possui como tema a formação inicial de professores de Geografia, no âmbito do Programa Institucional de Bolsa de Iniciação à Docência (PIBID). Buscou-se analisar o que fazem os egressos do Programa, no intuito de verificar quais são as contribuições do PIBID para os ex-participantes que estão atuando na Educação Básica. Para tanto, selecionou-se a pesquisa qualitativa, por meio do estudo de caso, com a participação dos 24 egressos do PIBID, formados no Curso de Licenciatura em Geografia da Universidade Estadual do Oeste do Paraná (UNIOESTE), campus de Marechal Cândido Rondon (MCR). Os resultados coletados indicam o impacto positivo na formação desses professores, contudo, apontam algumas dificuldades relacionadas com a inserção na carreira docente.
\end{abstract}

Palavras-chave: PIBID; egressos; formação inicial de professores de Geografia.

\begin{abstract}
:
The present work has as its theme the initial formation of Geography teachers, within the scope of the Institutional Program of Initiation to Teaching Grant (PIBID). We sought to analyze what the graduates of the Program do, in order to verify what the PIBID contributions are for the former participants who are working in Basic Education. For that, the qualitative research was selected, through the case study, with the participation of the 24 graduates of PIBID, graduated in the Degree of Geography in the State University of the West of Paraná (UNIOESTE), campus of Marechal Cândido Rondon (MCR). The results indicate the positive impact on the training of these teachers, however, they point out some difficulties related to the insertion in the teaching career.
\end{abstract}

Key-words: PIBID; graduate; initial formation of teachers of Geography.

\section{Introdução}

O início da carreira docente é uma das fases mais turbulentas da profissão, momento que o professor iniciante convive com incertezas e instabilidades, além de receber pouco apoio de seus pares. Nesse sentido, acredita-se que esse período requer atenção, visto que pode ser decisivo para alguns, no que diz respeito a permanecer ou não na profissão.

Deste modo, a presente pesquisa possui como tema a formação inicial de professores de Geografia, desenvolvida no Programa Institucional de Bolsa de Iniciação à Docência (PIBID), da Universidade Estadual do Oeste do Paraná (UNIOESTE), campus de Marechal Cândido Rondon (MCR).

Pressupõe-se que os egressos do PIBID tiveram a oportunidade de participar de experiências 
inovadoras durante o cursar da graduação e podem indicar quais são as suas percepções em relação às atuações no Programa, antes e depois de concluir a Licenciatura.

Portanto, pretende-se analisar as contribuições do PIBID para os professores em exercício na Educação Básica e que participaram do Programa, sobretudo para verificar o que fazem os expibidianos, formados no Curso de Licenciatura em Geografia da UNIOESTE/MCR, no período de 2011-2016.

Além disso, busca-se identificar quais são as dificuldades enfrentadas por esses profissionais, especialmente no que diz respeito à inserção na carreira docente como professores temporários ou concursados.

Para tanto, os dados foram analisados por meio da pesquisa qualitativa (ANDRÉ, 1983; GIL, 2002), mediante estudo de caso, com a participação dos 24 egressos do PIBID, através de entrevista semiestruturada (CANNEL; KAHN, 1974).

A quantidade de egressos entrevistados corresponde a totalidade dos ex-participantes licenciados entre os anos de 2011-2016. A entrevista foi realizada pela rede social Facebook (julho/2016), através de conversa, no intuito de facilitar a coleta de dados, visto que vários sujeitos da pesquisa moram em diferentes municípios do Paraná, e alguns mudaram seus endereços eletrônicos.

Constatou-se que 33\% dos egressos estão atuando na Educação Básica, visto que $42 \%$ dos expibidianos desenvolvem outros tipos de trabalho devido à falta de oportunidade para exercer a profissão docente.

Os dados obtidos nesta pesquisa podem contribuir com o fortalecimento de políticas de formação inicial de professores, em especial, o PIBID, na luta para que seja condizente com as políticas de valorização da carreira docente.

\section{PIBID de Geografia e seus egressos}

O Curso de Licenciatura em Geografia da UNIOESTE, campus de MCR, foi integrado ao PIBID em 2011, com início das atividades por meio do Subprojeto intitulado "O ensino da Geografia: da teoria à prática". Na primeira gestão (2011-2013), 28 acadêmicos bolsistas participaram do Subprojeto, além de 03 professores supervisores da Rede Pública de ensino do município de MCR.

A partir de 2014, o Subprojeto do PIBID-Geografia foi aprovado para mais quatro anos de atividades, no qual foram selecionados 12 acadêmicos bolsistas e 2 professores supervisores. Ressalta-se que outras 2 professoras da rede básica de ensino de MCR atuam no Subprojeto como voluntárias.

Desde julho de 2011 até julho de 2016, 33 licenciandos participaram do Subprojeto - com exceção dos 12 bolsistas no período da entrevista (2016). Desse total, 24 concluíram o Curso de Licenciatura em Geografia (73\%). Logo, um número significativo de licenciandos participaram do PIBID, sobretudo quando se considera que a cada ano forma-se em torno de 8 a 13 professores de Geografia (WILHELM, 2016).

Sabe-se que "A sala de aula traz, corriqueiramente, um número muito grande de variáveis complexas, diríamos até, incontroláveis [...]" (KAERCHER, 2014, p. 150). Portanto, ao analisar o contexto profissional dos egressos do PIBID, é possível compreender se o Programa tem a capacidade de contribuir e aproximar a formação inicial desenvolvida na Licenciatura, as disciplinas pedagógicas e o Estágio Supervisionado, do cenário encontrado nas escolas públicas da Educação Básica.

Nesse sentido, buscou-se sistematizar as características dos ex-participantes do PIBID de Geografia num quadro síntese (Quadro 01), que indica onde estão esses profissionais; o período que participaram do Programa; o ano de conclusão do Curso; se atuam na Educação Básica; se estão cursando ou já cursaram pós-graduação; e, por fim, qual é a atividade atual de cada um dos egressos. 
Quadro 01. Características dos Egressos do PIBID-Geografia da UNIOESTE/MCR

\begin{tabular}{|c|c|c|c|c|c|c|}
\hline Egressos & Município & $\begin{array}{c}\text { Período de } \\
\text { Participação no } \\
\text { PIBID } \\
\end{array}$ & $\begin{array}{c}\text { Ano de } \\
\text { Formação }\end{array}$ & $\begin{array}{l}\text { Prof. na Ed. } \\
\text { Básica? }\end{array}$ & $\begin{array}{c}\text { Possui Pós- } \\
\text { Graduação } \\
\text { (ano/conclusão)? }\end{array}$ & Atividade Atual \\
\hline 1)- $\mathrm{AO}$ & Itapoá-SC & $\begin{array}{l}\text { Jul/2011- } \\
\text { set/2011 } \\
(2 \text { meses })\end{array}$ & 2012 & $\begin{array}{l}\text { Sim, } \text { QPM }^{*} \\
(2 \text { anos })\end{array}$ & $\begin{array}{c}\text { Especialização em } \\
\text { Ed. do campo (2014) } \\
\text { e Ed. Especial } \\
(2015)\end{array}$ & $\begin{array}{c}\text { Professor da Educação Básica } \\
\text { e de cursinho preparatório } \\
\text { para vestibular }\end{array}$ \\
\hline 2)- ADK & Toledo-PR & $\begin{array}{c}\text { Jul/2011- } \\
\text { set/2012 } \\
(1 \text { ano/2 meses })\end{array}$ & 2013 & Não & $\begin{array}{c}\text { Mestrado em } \\
\text { Geografia (cursando: } \\
\text { 2016-2018) } \\
\end{array}$ & $\begin{array}{c}\text { Mestranda e Assistente em } \\
\text { Administração } \\
\text { (Concursada/UTFPR) }\end{array}$ \\
\hline 3)- BRF & Dourados-MS & $\begin{array}{l}\text { Fev/2012- } \\
\text { fev/2013 } \\
(1 \text { ano })\end{array}$ & 2014 & $\begin{array}{l}\text { Sim, } \text { PSS }^{* *} \\
\text { (lecionando há } \\
\text { 30 dias) }\end{array}$ & $\begin{array}{c}\text { Mestrado em } \\
\text { Geografia (cursando: } \\
\text { 2015-2017) }\end{array}$ & Mestranda e Professora \\
\hline 4)- BK & MCR-PR & $\begin{array}{l}\text { Jul/2011- } \\
\text { dez/2013 } \\
(2 \text { anos } / 5 \\
\text { meses) }\end{array}$ & 2013 & $\begin{array}{c}\text { Sim, QPM } \\
(1 \text { ano } / 4 \\
\text { meses })\end{array}$ & $\begin{array}{l}\text { Especialização em } \\
\text { História-Geografia } \\
\text { (início em } \\
\text { ago/2016) }\end{array}$ & Professora \\
\hline 5)- $\mathrm{CH}$ & $\begin{array}{c}\text { Nova } \\
\text { Santa Rosa-PR }\end{array}$ & $\begin{array}{c}\text { Jul/2011- } \\
\operatorname{dez} / 2013(2 \\
\text { anos/5 meses) }\end{array}$ & 2013 & Não & $\begin{array}{c}\text { Mestrado em } \\
\text { Geografia (2016) }\end{array}$ & $\begin{array}{l}\text { Aguardando ser chamada no } \\
\text { PSS e/ou no Concurso dos } \\
\text { Professores do Paraná }\end{array}$ \\
\hline 6)- DVS & $\begin{array}{c}\text { Assis } \\
\text { Chateaubriand- } \\
\text { PR }\end{array}$ & $\begin{array}{l}\text { Jul/2011- } \\
\text { dez/2013 } \\
(2 \text { anos } / 5 \\
\text { meses })\end{array}$ & 2013 & Não & $\begin{array}{c}\text { Mestrado em } \\
\text { Geografia (2016) }\end{array}$ & $\begin{array}{c}\text { Aguardando ser chamado no } \\
\text { PSS }\end{array}$ \\
\hline 7)- DR & MCR-PR & $\begin{array}{l}\text { Fev/2012- } \\
\text { jul/2012 } \\
\text { (6 meses) }\end{array}$ & 2012 & Não & $\begin{array}{c}\text { Mestrado em } \\
\text { Geografia (2015) }\end{array}$ & $\begin{array}{c}\text { Aguardando convocação no } \\
\text { PSS }\end{array}$ \\
\hline 8)- EW & Guaíra-PR & $\begin{array}{c}\text { Jul/2011- } \\
\mathrm{dez} / 2013(2 \\
\text { anos/5 meses) }\end{array}$ & 2013 & $\begin{array}{l}\text { Sim, PSS } \\
\text { (3 meses) }\end{array}$ & $\begin{array}{c}\text { Mestrado em } \\
\text { Geografia (2016) }\end{array}$ & $\begin{array}{l}\text { Professora PSS. Aguardando } \\
\text { chamamento do Concurso dos } \\
\text { Professores do Paraná }\end{array}$ \\
\hline 9)- EZM & MCR-PR & $\begin{array}{c}\mathrm{Abr} / 2012- \\
\mathrm{mar} / 2016 \\
(4 \text { anos })\end{array}$ & 2015 & Não & $\begin{array}{l}\text { Especialização em } \\
\text { Ed. Especial, (início } \\
\text { em ago./2016) }\end{array}$ & $\begin{array}{c}\text { Aguardando convocação no } \\
\text { PSS }\end{array}$ \\
\hline 10)- FM & Quatro Pontes-PR & $\begin{array}{l}\text { Ago/2012- } \\
\text { mar } / 2016 \\
(3 \text { anos } / 7 \\
\text { meses })\end{array}$ & 2016 & $\begin{array}{l}\text { Não, atuou no } \\
\text { PSS em } 2014 \\
(1 \text { ano })\end{array}$ & $\begin{array}{c}\text { Especialização em } \\
\text { Geografia } \\
\text { Econômica, } \\
\text { Educação e Pesquisa } \\
\text { (2011) }\end{array}$ & $\begin{array}{c}\text { Assistente administrativo pelo } \\
\text { PSS. Aguardando convocações } \\
\text { PSS para o exercício da } \\
\text { docência }\end{array}$ \\
\hline 11)- FAC & Corbélia-PR & $\begin{array}{c}\text { Jul/2011- } \\
\text { dez/2012 (1 } \\
\text { ano/5 meses) }\end{array}$ & 2012 & $\begin{array}{l}\text { Sim, PSS no } \\
\text { município (2 } \\
\text { anos) e no } \\
\text { Estado (6 } \\
\text { meses) }\end{array}$ & $\begin{array}{c}\text { Mestrado em } \\
\text { Geografia (2015) }\end{array}$ & Professora PSS \\
\hline 12)- ILS & MCR-PR & $\begin{array}{c}\mathrm{Jul} / 2011- \\
\mathrm{dez} / 2014 \text { (3 } \\
\text { anos/5 meses) }\end{array}$ & 2014 & Não & Não & $\begin{array}{c}\text { Caixa de } \\
\text { supermercado/aguardando } \\
\text { convocação no PSS }\end{array}$ \\
\hline 13)- JMW & MCR-PR & $\begin{array}{c}\text { Jul/2011- } \\
\text { dez/2012 (1 } \\
\text { ano/5 meses) }\end{array}$ & 2012 & $\begin{array}{l}\text { Não - Por falta } \\
\text { de } \\
\text { convocações } \\
\text { no PSS } \\
\end{array}$ & $\begin{array}{c}\text { Especialização em } \\
\text { Ed. Especial } \\
\text { Inclusiva (Cursando) }\end{array}$ & $\begin{array}{l}\text { Costureira/aguardando } \\
\text { convocação no PSS }\end{array}$ \\
\hline 14)- LMFL & MCR-PR & $\begin{array}{l}\text { Jul/2011- } \\
\text { dez/2011 } \\
\text { (5 meses) }\end{array}$ & 2011 & $\begin{array}{l}\text { Não - Por falta } \\
\text { de } \\
\text { convocações } \\
\text { no PSS }\end{array}$ & $\begin{array}{l}\text { Especialização em } \\
\text { Ed. Especial (2012) }\end{array}$ & $\begin{array}{l}\text { Representante Comercial de } \\
\text { Produtos Cosméticos }\end{array}$ \\
\hline 15)- LKKP & MCR-PR & $\begin{array}{l}\text { Jul/2011- } \\
\text { dez/2011 } \\
\text { (5 meses) }\end{array}$ & 2011 & Não & $\begin{array}{c}\text { Mestrado em } \\
\text { Geografia (2014) }\end{array}$ & $\begin{array}{c}\text { Professora no Ensino Superior } \\
\text { (Colaboradora) }\end{array}$ \\
\hline 16)- LV & MCR-PR & $\begin{array}{l}\text { Jul/2011- } \\
\text { dez/2011 } \\
\text { (5 meses) }\end{array}$ & 2016 & $\begin{array}{l}\text { Não- Por falta } \\
\text { de } \\
\text { convocações } \\
\text { no PSS }\end{array}$ & Não & $\begin{array}{c}\text { Supervisora de Vendas. } \\
\text { Aguardando convocação no } \\
\text { PSS }\end{array}$ \\
\hline 17)- $\mathrm{MCM}$ & Santa Helena-PR & $\begin{array}{c}\text { Set/2011- } \\
\text { abr/2013 } \\
\text { (1ano/7meses) }\end{array}$ & 2016 & $\begin{array}{l}\text { Sim, PSS } \\
\text { (3 meses) }\end{array}$ & Não & $\begin{array}{l}\text { Professora PSS/aguardando } \\
\text { ser chamada no Concurso dos } \\
\text { Professores do Paraná }\end{array}$ \\
\hline 18)- MPB & $\begin{array}{l}\text { Francisco } \\
\text { Beltrão-PR }\end{array}$ & $\begin{array}{c}\text { Set/2011- } \\
\text { jan/2013 (1 } \\
\text { ano/4 meses) }\end{array}$ & 2014 & Não & $\begin{array}{c}\text { Mestrado em } \\
\text { Geografia (cursando: } \\
\text { 2016-2018) } \\
\end{array}$ & Mestranda \\
\hline
\end{tabular}




\begin{tabular}{|c|c|c|c|c|c|c|}
\hline 19)- PLLF & Cascavel-PR & $\begin{array}{c}\text { Jul/2011- } \\
\text { dez/2012 (1 } \\
\text { ano/5 meses) }\end{array}$ & 2012 & $\begin{array}{c}\text { Sim, QPM (1 } \\
\text { ano/5 meses) }\end{array}$ & $\begin{array}{c}\text { Mestrado } \\
\text { (2015) }\end{array}$ & Professora \\
\hline 20)- PVDF & Cascavel-PR & $\begin{array}{c}\text { Jul/2011- } \\
\text { jul/2012 (1 ano) }\end{array}$ & 2014 & $\begin{array}{c}\text { Sim, QPM (1 } \\
\text { ano/5 meses) }\end{array}$ & Não & Professor \\
\hline 21)- RK & Cascavel-PR & $\begin{array}{c}\text { Dez/2012- } \\
\text { fev/2014 (1 } \\
\text { ano/2 meses) }\end{array}$ & 2016 & $\begin{array}{l}\text { Não, lecionou } \\
\text { como PSS } \\
\text { (3 meses) }\end{array}$ & $\begin{array}{c}\text { Mestrado em } \\
\text { Geografia (cursando: } \\
\text { 2016-2018) }\end{array}$ & Mestrando \\
\hline 22)-SAB & MCR-PR & $\begin{array}{c}\text { Out/2012- } \\
\text { fev/2014 (1 } \\
\text { ano/4 meses) }\end{array}$ & 2014 & Não & Não & $\begin{array}{l}\text { Atendente numa Floricultura. } \\
\text { Aguardando convocação no } \\
\text { PSS }\end{array}$ \\
\hline 23)- TKF & Curitiba-PR & $\begin{array}{c}\mathrm{Jul} / 2011- \\
\mathrm{dez} / 2011(5 \\
\text { meses) }\end{array}$ & 2012 & $\begin{array}{l}\text { Não, lecionou } \\
\text { como PSS } \\
\text { (4 meses) }\end{array}$ & Mestrado (2015) & $\begin{array}{c}\text { Professor no Ensino Superior } \\
\text { (Colaborador) e Doutorando } \\
\text { (UFPR) }\end{array}$ \\
\hline 24)-VFL & Santa Helena-PR & $\begin{array}{c}\text { Ago/2012- } \\
\text { dez/2013 (1 } \\
\text { ano/4 meses) }\end{array}$ & 2013 & $\begin{array}{l}\text { Não, lecionou } \\
\text { na Rede } \\
\text { Particular } \\
\text { (2 meses) }\end{array}$ & $\begin{array}{l}\text { Especialização em } \\
\text { Ed. Infantil } \\
\text { (cursando: 2015- } \\
\text { 2016) }\end{array}$ & $\begin{array}{l}\text { Instrutora de Cursos Livres no } \\
\text { CCICA***. Aguardando }^{\text {convocação no PSS }}\end{array}$ \\
\hline
\end{tabular}

Fonte: Dados coletados por meio de entrevista com os egressos do PIBID-Geografia (julho/2016).

${ }^{*}$ Quadro Próprio do Magistério - QPM; ${ }^{* *}$ Processo Seletivo Simplificado - PSS; ${ }^{* * *}$ Centro de Convivência Integral da Criança e Adolescente - CCICA.

De acordo com os dados dispostos no Quadro 01, existem 22 egressos do PIBID residindo no Estado do Paraná e 2 em municípios de outros estados: Itapoá-SC e Dourados-MS. Além desses, 9 expibidianos continuam em MCR, município onde se desenvolve o Subprojeto de Geografia da UNIOESTE.

O período de participação no PIBID é distinto de um egresso para outro. Alguns participaram por poucos meses (egresso no 1 - Quadro 1), devido à colação de grau ou motivos particulares, e outros durante os quatro anos do Curso (egresso no 9 - Quadro 1).

No que se refere ao ano de conclusão do Curso de Licenciatura em Geografia (UNIOESTE/MCR), verificou-se que duas egressas se graduaram em 2011, seis em 2012 e 2013, cinco em 2014, uma em 2015 e quatro no ano de 2016 (Quadro 01).

Constatou-se que oito ex-pibidianos exercem a profissão como professores na Educação Básica (33\%), sendo quatro vinculados ao Processo Seletivo Simplificado (PSS) ${ }^{1}$ e quatro concursados ${ }^{2}-$ Quadro Próprio do Magistério (QPM). Portanto, 16 egressos não lecionavam em escolas públicas no momento da entrevista (julho/2016), o que corresponde à 67\% dos sujeitos envolvidos no estudo. Contudo, desse total (67\%), ressalta-se que 2 egressos lecionam na Educação Superior ${ }^{3}$.

As atuações do PIBID-Geografia da UNIOESTE/MCR contribuíram de forma significativa na formação inicial dos egressos entrevistados, incentivando o desenvolvimento de pesquisas. Nota-se que $50 \%$ dos ex-pibidianos continuam aperfeiçoando sua formação, visto que sete egressos concluíram o mestrado e quatro estão cursando ${ }^{4}$. Além disso, um dos ex-participantes do Subprojeto está cursando doutorado 5 .

Também foram contabilizadas oito especializações, sendo que cinco egressos (21\%) não citaram a realização de uma pós-graduação. Para Sartori $(2011$, p. 6), preparar o professor para ensinar implica refletir o próprio ensino, com investigação e articulação entre teoria e prática. 0 autor considera importante a análise da prática para aperfeiçoá-la a partir das demandas que surgem no contexto escolar e de vida do aluno.

Nesse sentido, o PIBID contribui na formação docente, e aqueles que passaram por essa experiência reconhecem sua importância, especialmente porque os dados expostos no Quadro 01 indicam que os egressos do Programa continuam se aperfeiçoando na pesquisa e/ou no ensino.

Segundo Kaercher (2014, p. 233), “A universidade é uma das instâncias de formação do profissional

\footnotetext{
13); 8); 11); e, 17) (Quadro 01).

2 1); 4); 19); e, 20) (Quadro 01).

3 15) e 23) (Quadro 01).

4 Mestres: 5); 6); 7); 8); 11); 15); 19). Mestrandos: 2); 3); 18); 21) (Quadro 01).

5 23) (Quadro 01).
} 
e é preciso uma atitude ativa do graduando a fim de que ele não tenha a graduação como ponto final da sua formação". "É deste modo que se expande o repertório da ciência geográfica, tanto do ponto de vista teórico quanto metodológico" (WOITOWICZ, 2016, p. 108).

A profissão dos egressos do PIBID é diversa, alguns estão vinculados à docência (10), outros aguardam serem chamados no PSS (9) ou no Concurso dos Professores do Estado do Paraná (3), realizado em 2013.

Além disso, oito ex-pibidianos estão desenvolvendo atividades desligadas do magistério, sendo que uma egressa está concursada como Assistente em Administração pela Universidade Tecnológica Federal do Paraná (UTFPR) e não pretende seguir a carreira docente. Contudo, os outros sete egressos não tiveram oportunidade de atuar na profissão por falta de convocações no PSS, e desenvolvem outras funções, sobretudo no comércio (Quadro 01).

No geral, as características dos egressos do PIBID (2011-2016) indicam vínculo com a docência (42\%) e com a pesquisa (50\%), visto que muitos estão em formações complementares e/ou aguardam novas oportunidades para atuar como professor.

\section{As contribuições do PIBID para os egressos}

Por meio de entrevista semiestruturada, realizada com os 24 egressos do PIBID de Geografia da UNIOESTE/MCR (julho/2016), pela rede social Facebook, buscou-se verificar quais são as contribuições do Programa no exercício da Educação Básica. Para tanto, nesse trabalho será considerado os depoimentos dos 33\% dos egressos que estavam exercendo a profissão em escolas públicas, no momento da entrevista.

Nesse sentido, buscou-se sistematizar as respostas dos egressos no Quadro 02, para que os leitores possam "ouvir" esses profissionais e evidenciar as diferentes opiniões sobre as atuações no PIBID e seu impacto positivo na Educação Básica.

\section{Quadro 02 - Relações Estabelecidas com o PIBID no Exercício da Docência}

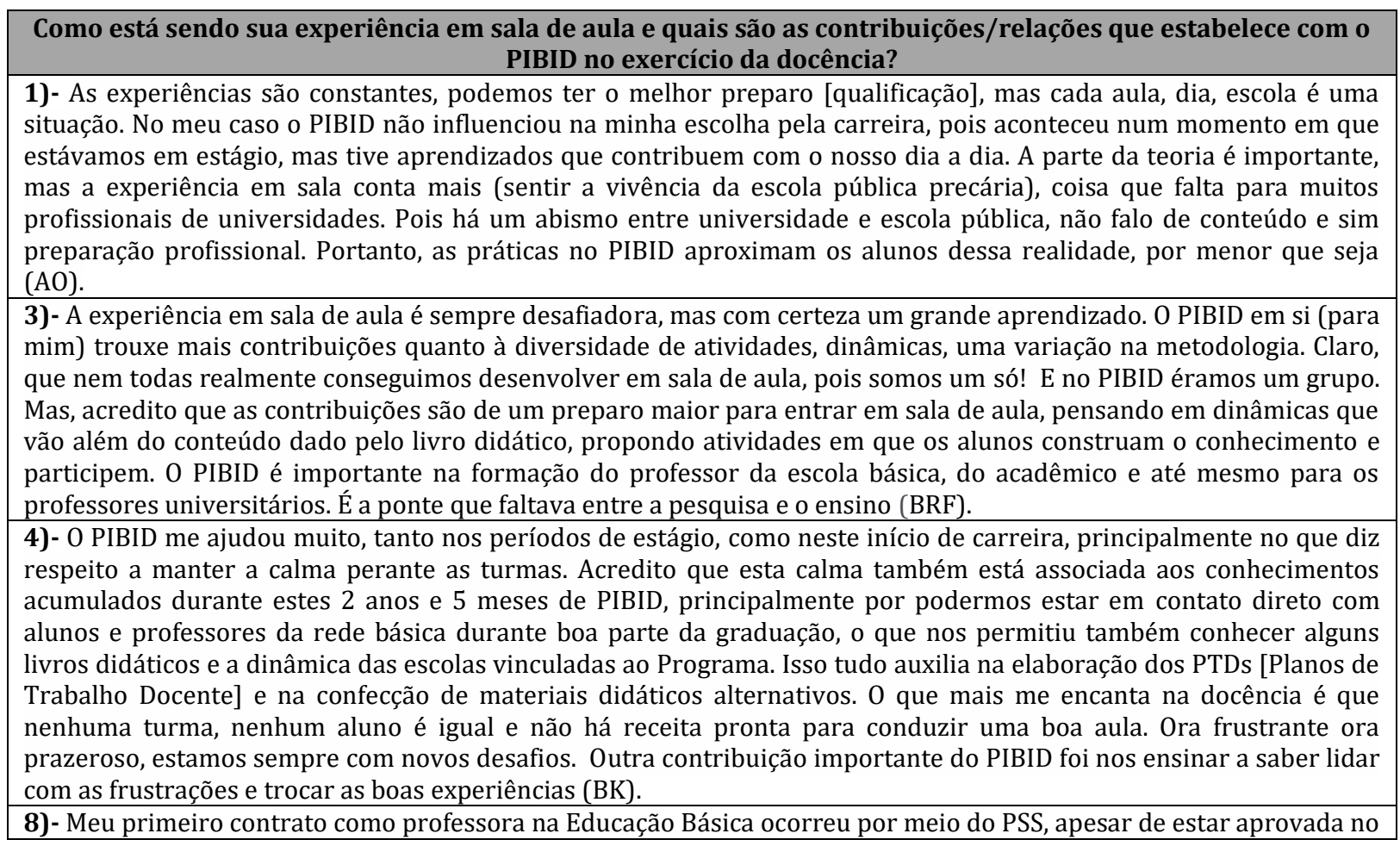


Concurso do Estado desde 2014, e ainda não ter sido convocada. 0 mais interessante foi que as minhas aulas aconteceram na Educação de Jovens e Adultos (EJA), contexto diferenciado do regular, do qual estava acostumada no PIBID, portanto, desafiador. Contudo, percebi que as contribuições do Programa durante o desenvolvimento do meu trabalho docente foram inúmeras, visto que senti facilidade de adaptação nesse novo ambiente escolar: o preenchimento de diários de classe, analisar o PPP e o regulamento interno da escola (e me preocupar em fazer essa análise), participar de reuniões pedagógicas e conselhos de classe, além do conhecimento das funções dos espaços escolares, eram situações familiares para mim. Aprendi tudo isso no PIBID, inclusive tive muita facilidade nos Estágios Supervisionados, tanto na graduação como no mestrado. Notei que desenvolver aulas diferenciadas faz parte da minha metodologia diária, sobretudo porque obtive esse incentivo durante o Curso de Licenciatura. Não é nada fora do comum e muito menos radical. Trata-se da reflexão constante sobre a prática de modo teorizado, e de utilizar as ferramentas didáticas presentes dentro da própria escola, muitas vezes esquecidas na gaveta (EW).

11) Bom, nem sempre é fácil lidar com os alunos. É uma diversidade muito grande de estudantes. Tenho alunos especiais e alguns desafios todos os dias. Acho que as atividades práticas do PIBID me ajudaram e me ajudam até hoje. Uso o livro do PIBID e tudo o que aprendi durante esse período de formação (FAC).

17)- Em sala de aula utilizo todo o conhecimento possível adquirido no Programa. Busco desenvolver as atividades realizadas no PIBID com os alunos, relacionando a teoria com a prática. Apesar dos diferentes desafios enfrentados como professora, as metodologias diferenciadas que aprendi mostram como o PIBID ainda é importante em sala de aula e na formação inicial de professores (MCM).

19)- Eu amo o que faço, com certeza não escolheria outra profissão. 0 PIBID me ajudou no Curso de Licenciatura e ainda contribui nas minhas práticas em sala de aula. Primeiramente porque me faz sempre pensar na importância de tornar o conhecimento lúdico e palpável para os alunos, principalmente do Ensino Fundamental. Também contribui na prática propriamente dita, porque consigo utilizar algumas atividades que desenvolvemos durante o PIBID e ideias práticas de outros subprojetos também. As atividades lúdicas do PIBID trazem inovação para as aulas de Geografia (PLLF).

20)- Olha, acho que as principais contribuições são na parte didática. Penso que pelo menos na parte que participei do Programa, faltou um pouco das contribuições das partes burocráticas da escola, por exemplo, trabalho em um colégio de periferia e existem muitas situações que não sabemos como agir: o tráfico de drogas, porte de armas, violência doméstica, a questão das religiões nas famílias... aprendemos na prática. Na parte didática aprendi muito, principalmente na preparação de aulas e atividades diversificadas. Foi excelente! Mesmo sabendo que a quantidade de tempo que temos para preparar aulas, corrigir trabalhos e provas é muito curta. Hoje faço até parte do conselho escolar da minha escola, de tanto que gosto do ambiente e me sinto parte dele. Esse espírito participativo foi estimulado no PIBID (PVDF).

Fonte: Dados coletados durante entrevista com os egressos do PIBID-Geografia (julho/2016).

Ao analisar o Quadro 02, observou-se que para 87\% dos egressos que atuam na Educação Básica, o PIBID foi importante principalmente por estimular o desenvolvimento de metodologias e atividades didáticas diferenciadas, tornando a aula mais interessante para os alunos.

Considera-se cada escola, turma e aula especial, por ser única dentro do seu contexto. Entre momentos prazerosos e de frustração, o PIBID contribuiu para o entendimento das diferentes situações possíveis de serem encontradas no ambiente escolar, sobretudo em relação aos aspectos emotivos presentes numa sala de aula.

"Esse vínculo entre os aspectos emocionais e cognitivos da identidade profissional docente deve ser levado em conta na hora de analisar a profissionalização docente" (GARCIA, 2010, p. 14), os quais podem tornar o trabalho do professor(a) menos desgastante, quando trabalhados na formação inicial.

As ações desenvolvidas no PIBID facilitaram a adaptação dos egressos em novos ambientes escolares, visto que $62 \%$ dos professores recém-formados se consideraram mais preparados e seguros no exercício da profissão, devido ao contato com a sala de aula desde o início da Licenciatura, viabilizado pelo Programa.

Um dos egressos relatou que se sente parte do ambiente escolar e por isso busca participar das discussões e ações pedagógicas, visando sua melhoria (Egresso 20, Quadro 02). Segundo Cruz (2007, p. 202), os professores precisam participar mais do processo de reformulação curricular. Necessitam assumir a posição de sujeitos construtores das diretrizes curriculares para ocorrerem menos conflitos entre o que se propõe e o que se faz.

Nesse sentido, o PIBID é exemplo na formação inicial docente, sobretudo por se preocupar em estabelecer o compromisso participativo do futuro professor, nas mais diversas instâncias. Além disso, o Programa estimula a continuidade dos estudos dos participantes, independente da dicotomia existente entre Geografia Física e Humana, sendo que existem egressos em diferentes programas de 
mestrado e doutorado (50\%).

Assim, o PIBID estimula o trabalho docente com práticas diferenciadas que vão além do livro didático, embora, este último seja frequentemente utilizado como base de análise e no planejamento das atividades. Aqueles que se encontram no exercício da profissão docente intitulam-se realizados assumir o contrário seria pesaroso -, apesar das precárias condições de trabalho, amam a profissão. Contudo, 42\% dos egressos aguardam oportunidades para lecionar na Educação Básica, tanto por meio do PSS como pelo Concurso Público do Estado do Paraná (2013).

\section{Considerações Finais}

Diante das discussões expostas, pode-se constatar que o modelo de formação adotado no PIBID de Geografia, de modo complementar ao Curso de Licenciatura (UNIOESTE/MCR), tem ajudado o recémformado na Universidade a enfrentar as complexidades do trabalho docente, principalmente por facilitar a adaptação dos egressos em novos ambientes escolares, além de instigar o desenvolvimento de aulas diferenciadas e a elaboração de pesquisas.

Verificou-se que 33\% dos ex-pibidianos exercem a profissão docente na Educação Básica, o que demonstra insuficiente oferta de oportunidades para totalidade dos recém-formados, além da morosidade no processo de chamamento dos professores aprovados em concurso público do magistério.

Além disso, observou-se que 50\% dos egressos continuam aperfeiçoando sua formação, visto que 8 concluíram o mestrado, 4 estão cursando e 1 é doutorando. A proximidade com o ensino, a pesquisa e a extensão viabilizada pelo Programa foi crucial nesse aspecto, uma vez que o incentivo da reflexão teórica sobre a prática é constante nas atividades do PIBID e se faz necessária na profissão docente.

Apesar das contribuições do Programa durante a formação inicial de professores de Geografia, relatada pelos egressos em entrevista, constatou-se que $42 \%$ dos ex-participantes do PIBID ainda não tiveram oportunidade de exercer a profissão na Educação Básica, sobretudo por falta de convocações no PSS ou no Concurso Público do Estado do Paraná (2013).

Nesse sentido, a valorização da profissão docente proporcionada pelo PIBID, acaba sendo limitada ao Curso de Licenciatura, promovendo status diferenciado de formação e qualificação durante a graduação.

Depois de formado, o professor iniciante encontra dificuldades de inserção na carreira, visto que o PIBID e as experiências extracurriculares adquiridas na Licenciatura não são considerados nos processos seletivos e concursos do Estado (Paraná), diminuindo a classificação desses profissionais, que por sua vez, não são convocados ou esperam por muito tempo, ocorrendo casos de desistência da profissão.

Deste modo é preciso destacar que o PIBID cumpre com sua missão principal: incentivar e aperfeiçoar a formação inicial de professores. Entretanto, garantir que esses profissionais atuem na Educação Básica não é tarefa do PIBID, e muito menos da Universidade, mas sim do governo, que precisa motivar a escolha dos jovens pela docência, mas também oferecer subsídios para sua permanência e avanços na carreira conforme titulação.

Talvez, seja esse o principal motivo para muitos egressos do Programa seguirem nos cursos de mestrado e doutorado (o que é excelente!), aperfeiçoando sua formação e buscando novos campos de trabalho, os quais são muito mais competitivos, mas simultaneamente, mais valorizados.

Espera-se que as discussões deste trabalho se ampliem no âmbito das IES, para que seja possível conhecer o contexto estadual, regional ou mesmo nacional dos egressos do PIBID, viabilizando o conhecimento de dados concretos sobre o Programa e das condições de trabalho dos professores em início de carreira. 
O desejo e a luta estão centrados na ampliação e fortalecimento do PIBID, mas também, por incentivos governamentais que amparem e valorizem de fato os professores iniciantes, evitando o crescimento dessa contradição na formação e na inserção da profissão docente.

Destaca-se que esses resultados foram obtidos durante o curso de mestrado (2016) e serão aprofundados na pesquisa de doutorado (UNIOESTE/Francisco Beltrão), ampliada para nível estadual (Estado do Paraná). Ademais, acredita-se que a pesquisa poderá contribuir com a reformulação de políticas de formação de professores, coerentes com as políticas de valorização da profissão.

\section{Referências}

ANDRÉ, Marli E. D. A. Texto, contexto e significado: algumas questões na análise de dados qualitativos. Cadernos de Pesquisa, (45): 66-71, 1983.

AZEVEDO, Maria Antonia Ramos de; ANDRADE, Maria de Fátima Ramos de. 0 conhecimento em sala de aula: a organização do ensino numa perspectiva interdisciplinar. Educar, Curitiba, n. 30, p. 235-250, 2007.

CANNEL, C. F.; KAHN, R. L. Coleta de dados por entrevista. In: FESTINGER, L.; KATZ, D. A Pesquisa da Psicologia Social. Rio de Janeiro: Fundação Getúlio Vargas, 1974.

CRUZ, Giseli Barrreto da. A prática docente no contexto da sala de aula frente às reformas curriculares. Educar, Curitiba, №. 29, p. 191-205, 2007.

GARCIA, Carlos M. O professor iniciante, a prática pedagógica e o sentido da experiência. Formação Docente, Belo Horizonte, v. 02, n. 03, p. 11-49, ago./dez. 2010.

GIL, Antonio Carlos. Como elaborar projetos de pesquisa. 4. ed. São Paulo: Atlas, 2002.

IMBERNÓN, Francisco. La Formación y el Desarrollo Profesional del Profesorado: hacia una nueva cultura profesional. Barcelona: Graó, 1994.

KAERCHER, Nestor A. Se a Geografia escolar é um pastel de vento o gato come a Geografia Crítica. Porto Alegre-RS: Evangraf, 2014.

LIMA FILHO, Jorge Ferreira de. O ensino de geografia e as novas tecnologias: perspectivas para o uso de softwares educacionais como recurso didático. João Pessoa, 2013. 175 p. Dissertação (Mestrado em Geografia) - Universidade Federal da Paraíba.

NÓVOA, António. Professores: imagens do futuro presente. Lisboa: EDUCA, 2009.

PORTUGAL, Jussara Fraga. Memórias, diários e portfólios: narrativas autobiográficas e formação docente. In: PORTUGAL, Jussara Fraga; CHAIGAR, Vânia Alves Martins (Org). Ensino e pesquisa em educação geográfica: memórias, histórias de vida e narrativas docentes. Salvador: EDUFBA, 2015, p. 43-72.

SARTORI. Jerônimo. Formação de professores: conexões entre saberes da universidade e fazeres na educação básica. PROGRAD. 2011.

TARDIF, Maurice. Saberes docentes e formação profissional. Petrópolis, RJ: Vozes, 2002.

WILHELM, Marilene Franciele. A Evasão do Curso de Licenciatura em Geografia da Universidade Estadual do Oeste do Paraná, campus de Marechal Cândido Rondon, nos anos de 2012 a 2015. 2016. 115 p. Trabalho de Conclusão de Curso (Licenciatura em Geografia) - Universidade Estadual do Oeste do Paraná (UNIOESTE), Marechal Cândido Rondon-PR.

WOITOWICZ, Eliete. A Formação Inicial de Professores de Geografia no PIBID/UNIOESTE - Campus de Marechal Cândido Rondon-PR (2011-2015). 2016. 144 p. Dissertação (Mestrado em Geografia) Universidade Estadual do Oeste do Paraná (UNIOESTE), Francisco Beltrão-PR. 